\title{
Thirteen years of drifting data. Surface currents in the Canary Islands region.
}

\author{
L. Cardona ${ }^{1}$, M. Villagarcía ${ }^{1}$, Pérez-Marrero', R. Santana ${ }^{2}$, A. Cianca ${ }^{1}$, \\ C. Barrera ${ }^{3}$, C. Llerandi ${ }^{1}$, D. Vega-Moreno ${ }^{2}$, M.J. Rueda ${ }^{1}$ and O. Llinás ${ }^{3}$. \\ 1. Canary Institute of Marine Sciences \\ 35200 Telde. Gran Canaria, Spain. \\ 2. University of Las Palmas de Gran Canaria \\ 35017 Campus de Tafira. Canaria, Spain. \\ 3. Oceanic Platform of the Canary Islands, PLOCAN \\ 35214 Telde, Gran Canaria.
}

\begin{abstract}
During the last thirteen years 121 NOAA drifters have been deployed at the ESTOC site (European Station for TimeSeries in the Ocean, Canary Islands), located in the North Atlantic $\left(29^{\circ} 10^{\prime} \mathrm{N}, 1^{\circ} 30^{\prime} \mathrm{W}\right)$, ranging in time from 1998 to nowadays. The study of their trajectories has provided a good knowledge about the surface current system in this area. Wind and current data have also been added to improve the results. All this information has been implemented into a model intended to cover marine emergency situations in the Canarian archipelago waters, such as search and rescue operations and pollutant dispersal. The aim is to develop an Operational System, based in the combination of observations and analyses of oceanographic data with numerical simulation, in order to predict the drifting objects trajectories.
\end{abstract}

\section{INTRODUCTION}

The data set used belongs to the program Surface Velocity Program (SVP), and was handled as part of the collaboration between the Canary Islands Institute of Marine Sciences (ICCM) and the AOML (Atlantic Oceanographic and Meteorological Laboratory) of the NOAA (National Oceanic and Atmospheric Administration). From the start of this collaboration in 1998, a drifting buoy was launched every month at the European Oceanographic Station ESTOC, located 60 miles north of Gran Canaria; a total of 122 drifting buoys have been deployed in the water until nowadays.

Currently all the data collected with these buoys are being processed to establish the patterns of subsurface currents, studying their seasonality and variability in the environment of the Canary Islands archipelago. These data can be integrated into predictive models of drifting objects, in order to provide assessment in the possible events of human or material loss due to maritime accidents.

In the eastern Atlantic, the circulatory flow of the subtropical gyres recirculates a considerable amount of waters that enters this eastern basin across the central Atlantic ridge, mostly to the south and, to a lesser extent, to the north of the Azores. The main transport is concentrated in the Azores current and continues towards the east following the zonal currents of the Azores Front, where the anticyclonic flow turns and braches into three currents in the Canary Basin. The firs branch flows very close to the eastern flank of the central Atlantic ridge; the second is located in the central Canary Basin; and the third circulates around Madeira and constitutes the Canary Current.

The Canary Current is strongly influenced by the seasonal variation of the trade winds and the resulting upwelling of northwest Africa. In Winter (February, March and April) the trade winds spread towards the south. In Summer (August, September and October) the centre of the high system drifts towards the north, hence moving to the north the southern boundary of the trade winds.

\section{DRIFTING BUOY}

Since the 1970s, many drifting buoys have been deployed as part of a wide range of scientific studies. This drifter consists of a surface buoy and a subsurface drogue (sea anchor), attached by a long, thin tether. The buoy measures temperature and other properties, and has a transmitter to send the data to passing satellites. The drogue dominates the total area of the instrument and is centered at a depth of 15 meters beneath the sea surface. Each drifting buoy can be fitted with a range of sensors to measure the surface temperature of the sea, barometric pressure, salinity, wind speed and direction, etc. The buoy also carries sensors testing for submersion and tension on the tether, to prove that the drogue is still attached. Drifter locations are estimated from Argos, a satellite-based system for collecting, processing and distributing data, which is operated by Collecte Localisation Satellites in Toulouse, France.

The Drifter Data Assembly Centre run by NOAA/AOML is based in Miami, Florida. The mission of the centre is to collect the data, verify their quality, interpolate them at six hours intervals and keep them in the database which can then be consulted online. The database currently contains the data from 13.876 SVP drifting buoys deployed since 1979 . The data collected from this array of buoys comes from many countries participating in the Global Drifting program.

There are two basic sizes of SVP drifters: the original, relatively heavy SVP drifter and the newer "mini" version. The less expensive, easier-to-deploy mini design was proposed in 2002 and is currently produced alongside original SVP drifters by several manufacturers. Manufacturers of SVP drifters include Clearwater Instrumentation (Watertown, MA USA), Marlin- 
Yug (Sevastopol, Ukraine), Metocean Data Systems (Dartmouth, Nova Scotia, Canada), Pacific Gyre (Oceanside, CA USA), and Technocean (Cape Coral, FL USA).

\section{Technical specifications of the buoys}

The surface float ranges from $30.5 \mathrm{~cm}$ to $40 \mathrm{~cm}$ in diameter. It contains: batteries in 4-5 packs, each with 7-9 alkaline D-cell batteries; a transmitter; a thermistor to measure sea surface temperature; and possibly other instruments measuring barometric pressure, wind speed and direction, salinity, and/or ocean colour. They also have a submergence sensor or a tether strain sensor to verify the presence of the drogue.

The drogue is centred at 15 meters beneath the surface to measure mixed layer currents in the upper ocean. The outer surface of the drogue is made of nylon cloth. In the original design it is 7 sections, each $92 \mathrm{~cm}$ long and $92 \mathrm{~cm}$ in diameter, for a total length of $6.44 \mathrm{~m}$. Mini drogues are not yet standardized among the manufacturers: they are 4 (Pacific Gyre) or 5 (Marlin-Yug) sections of original dimensions, or 4 (Clearwater) or 5 (Technocean) redesigned sections of diameter $61 \mathrm{~cm}$, length $1.22 \mathrm{~m}$ per section.

Throughout the drogue, rigid rings with spokes support the drogue's cylindrical shape. The drogue is a "holey-sock": each drogue section contains two opposing holes, which are rotated 90 degrees from one section to the next. These holes act like the dimples of a golf ball by disrupting the formation of organized lee vortices.

While the size of the surface float and drogue vary, the manufacturers all aim for a specific nondimensional goal: a drag area ratio of 40. This ratio is the drag area (drag coefficient times cross-sectional area) of the drogue, divided by the drag area of all other components. At a drag area ratio of 40, the resulting downwind slip (defined later) is $0.7 \mathrm{~cm} / \mathrm{s} \mathrm{in} 10 \mathrm{~m} / \mathrm{s}$ winds (Niiler and Paduan, 1995). The nominal lifetime of the satellite transmitter is 450 days. A drogue generally remains attached to a buoy for 300 days.

\section{RESULTS}

The results of the annual surface circulation in the Canaries archipelago obtained from drifting buoys have provided a good knowledge of the surface current system in this area. It also confirms the variability in current direction as an indicator of the tendency for gyres to appear in the centre of the Canary Current. Two clear routes have been confirmed: one flowing southwards, in the lee of the archipelago, which coincides perfectly with classic descriptions; and another less known westward route, which would channel part of the volume of water flowing out towards the west without crossing the archipelago. The figure (1) shows that the clearest zone adjoining the African coast indicates an absence of data, as no buoy reached the area due to intense, generally south-westerly circulation generated by the upwelling of the African coast.

Figure1. Mean observations for the period 1998-2005, for each $1^{\circ} \times 1^{\circ}$ longitude/ latitude grid cell, of the presence of buoy (colour scale) and current flow direction (vector).

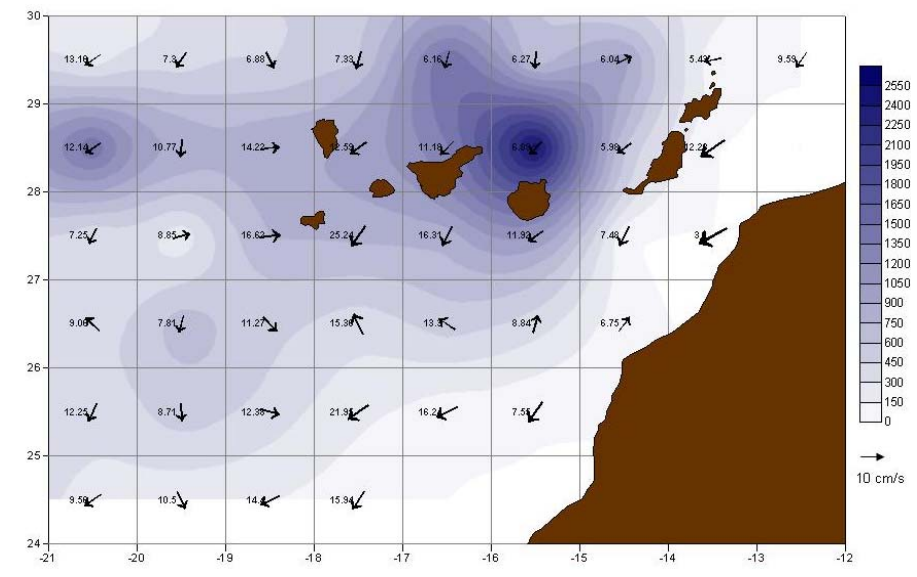

The proximity of the upwelling area in the African coast and the obstacles that represent the islands in the mean circulation provide a significant number of mesoscale structures crossing the survey area. Stationary cyclonic and anti-cyclonic eddies are visible to the south of the islands. These structures can be estimated by making use of satellite altimeters (T/P-ERSJason). This information has allowed us to compare the structures observed from satellites with drifting buoys deployed in the area. 
Figure2. The trajectories of a buoy deployed at ESTOC that was drifted by these mesoscales structures for a long period of time.

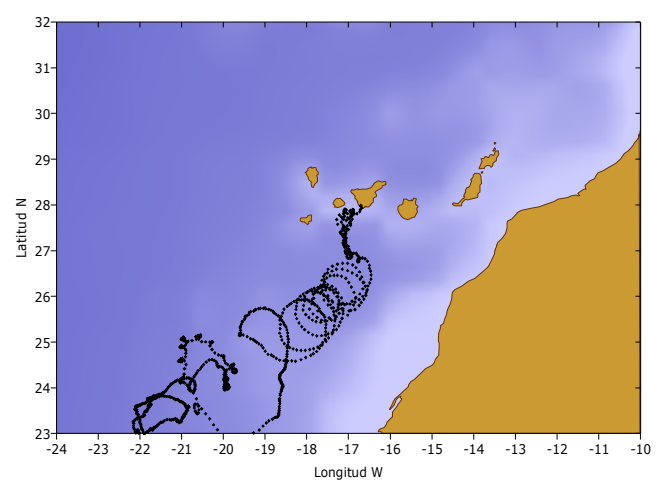

\section{APPLICATIONS}

An Operational Oceanography System is being implemented, based in the combination of observations and analyses of oceanographic data with numerical simulation, in order to try predicting the drifting object trajectories. It is intended to cover marine emergency situations in the Canarian Archipelago waters, like research and rescue operation. The buoys trajectories are used for the calibration of the results obtained by the models. The development of the model is by means of the hydrodynamic equation and the most probable trajectory is obtained for the initial conditions.

Figure4. Buoy trajectory (in blue) and trajectory obtained as a result of the model (in brown)

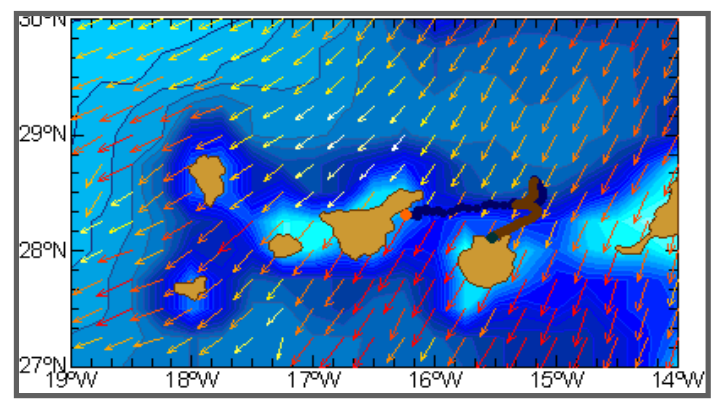

\section{ACKNOWLEDGMENT}

The authors want to give special thanks to the Drifter Data Assembly Center (DAC) from the AOML/NOAA, for the availability of the data used to do this work, as well as the quality and control analysis of the data before was distributed.

Special gratitude to Shaun Dolk and Dr Rick Lumpkin from AOML and to Mayra Pazos from the NOAA/AOML's drifter Data Assembly Center (DAC).

\section{REFERENCES}

[1] Hansen, D.V.; Poulain, P.MQuality Control and Interpolations of WOCE-TOGA Drifter Data. Journal of Atmospheric and Oceanic Technology, N ${ }^{\circ}$ 13, pp. 900-909, 1996.

[2] Lumpkin, R.. Decomposition of surface drifter observations in the Atlantic Ocean. Geophysical Research Letters, 30, NO.14, pp.1753, 2003

[3] Niiler, P.P.; Paduan, J.D. Wind-Driven Motions in the Northeast Pacific as Measured by Lagrangian Drifters. Journal of Physical Oceanography, No 25, pp. 2819-2830, 1995.

[4] Otto L.; Van Aken, H.M. Surface circulation in the northeast Atlantic as observed with drifters. Deep-Sea Research I, 43, NO.4, pp.467-499, 1996.

[5] Sombardier, L.; Niiler, P.P. Global Surface Circulation Measured by Lagrangian Drifters. Sea Technology, pp. 21-24, 1994.

[6] Toner, M., A. D. Kirwan, L. H. Kantha, and J. K. Choi, Can general circulation models be assessed and their output enhanced with drifter data?. J. Geophys. Res. 106(C9), 19, pp.563-579, 2001.

[7] UNESCO. Guide to Drifting Data Buoys. IOC/WMO Manual and Guides, n²0, 1998.

[8] Zhou, M.; Paduan, J. D.; Niiler, P.P. Surface currents in the Canary Basin from drifters observations. Journal of Geophysical Research. 105, NO.C9, 21,893-21,911, 2000 